\title{
Resistir ao presente: tensionando heranças modernas para pensar a Educação Ambiental
}

\section{Resisting the present: subjecting modern heritages to stress in order to think about Environmental Education}

\author{
Paula Corrêa Henning ${ }^{1}$ \\ https://orcid.org/0000-0003-3697-9030
}

\begin{abstract}
Resumo: $\mathrm{O}$ artigo objetiva analisar o discurso inicial da ciência moderna como uma das condições de possibilidade para emergência da crise ambiental. Para isso, analisa o Novum organum, de Francis Bacon e $O$ discurso do método, de René Descartes. A partir dos estudos foucaultianos sobre a função-autor e a atualização dos ditos no contemporâneo, busca-se elementos para problematizar o eterno retorno de nossas heranças modernas. Dá-se visibilidade a três reativações discursivas: aos modos atuais de encarar a ciência; a dupla posição do humano hoje e a objetificação da natureza. Abordando os fundamentos históricos, epistemológicos e filosóficos da Educação Ambiental (EA), esse artigo busca contribuir para pensarmos na responsabilidade dos professores e pesquisadores desse campo, olhando de modo provocativo para a crise ambiental que experienciamos. Examinando a crise, talvez pudéssemos, com o auxílio dos fundamentos da EA, tensionar nossas heranças modernas. Não para negá-las, mas para potencializar o desejo de resistir ao presente.
\end{abstract}

Palavras-chave: Educação ambiental. Natureza. Filosofia da ciência. Crise ambiental. Michel Foucault.

\begin{abstract}
This article aims to analyze the discourse of modern science as a possible condition for the emergence of the environmental crisis. Thus, it analyzes Novum organum, by Francis Bacon, and Discourse on the method, by René Descartes. Elements that problematize the forever return of our modern heritage are sought, based on Foucauldian studies about the author function and the updating of current speech contemporary discourse. Visibility is given to three discursive reactivations: the current manner of facing science; the dual position of individuals today, and the objectification of nature. Provocatively looking into the ongoing environmental crisis, this article seeks to induce thinking about teachers' and field researchers' responsibilities by addressing the historical, epistemological and philosophical foundations of environmental education. By examining the crisis, with help of the foundations of environmental education, we may be able to tension our modern heritages not to deny them, but instead to intensify in ourselves the desire to resist the present.
\end{abstract}

Keywords: Environmental education. Nature. Philosophy of science. Environmental crisis. Michel Foucault.

${ }^{1}$ Universidade Federal do Rio Grande (FURG), Instituto de Educação, Programa de Pós-Graduação em
Educação Ambiental, Rio Grande, RS, Brasil. E-mail: paula.c.henning@gmail.com 


\section{Introdução}

É preciso acolher cada momento do discurso em sua irrupção de acontecimento; na pontualidade em que ele aparece e na dispersão temporal que lhe permite ser repetido, sabido, esquecido, transformado, apagado até em seus menores traços, enterrado, bem longe de qualquer olhar, na poeira dos livros (FOUCAULT, 2005, p. 95).

O discurso como um acontecimento. É desse lugar que parto para escrita desse artigo. É desse lugar, perigoso e produtivo, que olho para o passado com os olhos do presente. Uma provocação aos modos como nos fabricamos sujeitos em tempos de crise ambiental. Vivemos, a cada dia, ouvindo as ameaças de um colapso em nosso planeta: o derretimento de geleiras; o aquecimento global; os refugiados climáticos; a extinção de espécies animais; dentre tantas outras problemáticas que se apresentam aos nossos olhos cotidianamente. Para pensar sobre isso, não se trata de ir nas raízes da crise, no ímpeto desejo moderno de encontrar a verdadeira resposta para ela. Trata-se, isto sim, de pensar nosso presente, de olhar os modos como se gesta uma crise frente ao nossos diferentes modos de nos relacionarmos com a natureza.

Foucault (1995) e Deleuze (1988) nos convidam a resistir ao presente. Penso que um dos exercícios da Educação Ambiental (EA) é esse. Daí cabe a pergunta: mas que presente é este? Para sabermos ao que resistir é preciso entender a nossa atualidade e aqui a história pode nos ajudar. Para examinar nosso entorno cabe entender como se fabricaram as condições de possibilidade para chegada em nosso presente. Nesse artigo, interessa, em específico, como chegamos ao tempo denominado por nós como crise ambiental? Quais suas condições de existência? Ao pensarmos sobre isso, o campo da Educação pode resistir ao presente, pensar sobre como nos tornamos aquilo que somos, como nos fabricamos apartados da natureza?

Esse ensaio deseja criar condições para que, nós, professores e pesquisadores, entendamos os tributos da ciência moderna em nossos modos de existir e conviver com a natureza. Problematizando as condições de emergência para isso, cabe a nós, na tarefa de educar, tensionar o pensamento do aluno, dar vazão ao hoje, potencializar seus efeitos e provocar a seara educativa: o que pode a Educação Ambiental em tempos de crise?

Com o exercício filosófico podemos pensar sobre nossas condições históricas de existência. Não há uma verdade sobre o que é mesmo o sujeito, ou ainda, sobre o que é mesmo a natureza. Essas verdades, assumidas/fabricadas pelo mundo moderno nos constituem enquanto sujeitos desse tempo. É dizer, "Isto que chamamos 'natureza' é parte e resultado de uma longa história cultural e de uma aplicada atividade humana” (CASTRO, 2007, p. 5, grifo do autor).

Com esses contornos teóricos, o presente artigo toca numa área ainda bastante carente no campo da Educação Ambiental: os seus fundamentos. Seu objetivo é analisar como o discurso inicial da ciência moderna pode ser entendido como uma das condições de possibilidade para emergência da crise ambiental. Para isso, tomo dois clássicos da Ciência Moderna, $\mathrm{O}$ Novum organum, de Francis Bacon, publicado em 1620, e $O$ discurso do método de René Descartes (de 1637), e para eles olho com um apagamento de suas assinaturas. Não mais o autor, mas as atualizações que se derivam no hoje. Imbuída do pensamento foucaultiano a respeito da função-autor (FOUCAULT, 2001), busco elementos que dão a ver o desejo de domínio e exploração da natureza, com Bacon e Descartes e suas potências atuais. A seguir, à guisa 
de fechamento, busco problematizar o lugar da Educação Ambiental diante desse cenário. Tensionando nossos modos de enxergá-la como uma solução para o problema posto, gostaria de provocar o leitor a respeito das ações políticas possíveis em nosso trabalho docente.

Analisando o campo histórico, epistemológico e filosófico da Educação Ambiental, concordo com Mauro Grün (GRÜN, 1996) a respeito da necessidade de pensarmos nos pressupostos que contribuem para emergência da Educação Ambiental. Abordando os fundamentos da EA, esse artigo pode contribuir para pensarmos sobre nosso lugar e nossa responsabilidade enquanto pesquisadores desse campo, olhando de modo provocativo para a crise ambiental que experienciamos. Talvez entendendo alguns elementos da nossa história moderna, que deram condições para cisão humano-natureza e, atualmente, para uma preocupação com a natureza, a Educação Ambiental possa contribuir com um olhar problematizador a respeito das nossas heranças. Meu desejo é evidenciar como os fundamentos históricos, epistemológicos e filosóficos da EA podem favorecer para colocarmos em exercício aquilo que Foucault (2014) nos ensinou: a problematização histórica do nosso presente. Trata-se do exercício do pensamento para tensionar em nós o desejo de debruçar-nos sobre os acontecimentos e, quiçá, criar potência em nossas práticas cotidianas enquanto educadores ambientais. Somente entendendo a história e exercendo um olhar filosófico sobre ela, poderemos tensionar as verdades que nos habitam e criar fissuras possíveis nos nossos modos de enxergar nossa relação com a natureza. Essa, a meu ver, é uma das importantes contribuições da EA que passa, sem dúvida, por mirar seus fundamentos.

É desse lugar interessado e sitiado pela perspectiva pós-estruturalista em educação, que o estudo é tecido. Vejo a produtividade de olhar alguns acontecimentos que foram fabricando nossas maneiras de ser e se comportar diante da natureza. "[...] examinar os contornos que, num lugar e numa época, funcionaram como condições de possibilidade para que se engendrasse" uma determinada crise (VEIGA-NETO, 2015, p. 29), é o que persigo nesse texto. Por isso, opto por olhar Bacon e Descartes na sua pontualidade, naquilo que, hoje, lhes permitem ser repetidos e também apagados, lá onde o cheiro da poeira dos livros nos convida a mirar.

\section{Do apagamento de Bacon e Descartes ou da atualização de seus ditos}

"Saber é poder" (BACON, 1979). "Penso logo existo" (DESCARTES, 1996). A proposição científica de Bacon e o cogito de Descartes são tomadas aqui como matrizes do Pensamento Moderno. É a partir deles e com eles que a ciência - enquanto inscrita na Modernidade - passa a existir. A imponência do saber e a lógica cartesiana explicam as coisas do mundo. Mas não é somente isso. Além de explicar, agem sobre ele. Um de seus objetos de domínio é a natureza.

Hoje, muitos de nós, uma grande maioria de pesquisadores, criticam as bases imparciais do método científico (GRÜN, 1996). No entanto, não há dúvida que a ele devemos uma revolução científica nunca antes imaginada pela humanidade - e também pela natureza. Justo por isso se trata de tomá-los como potentes discursos que foram fabricados para além do autor, como entidade estabelecida. E é nesse sentido que, concordando com Foucault, tomo os escritos de Bacon e Descartes numa posição transdiscursiva. 
Ora, é fácil ver que, na ordem do discurso, pode-se ser o autor de bem mais que um livro - de uma teoria, de uma tradição, de uma disciplina dentro das quais outros livros e outros autores poderão, por sua vez, se colocar. Eu diria, finalmente, que esses autores se encontram em uma posição transdiscursiva (FOUCAULT, 2001, p. 280).

Colocando os fundadores da ciência nesta posição, Foucault tenta demarcar o quanto seus escritos são potentes o suficiente para produzir um discurso tamanho, que repercute em nossa sociedade, seja naquele momento histórico, seja, atualizado, em nosso tempo. Um discurso de ciência, um discurso de natureza que merece nosso debruçar, buscando entender as condições de seu funcionamento, o modo como se fabricou um certo olhar para a natureza. E na medida em que a escrita de um livro é entendida como um espaço em que o sujeito, incessantemente, “[...] não para de desaparecer” (FOUCAULT, 2001, p. 268), devemos olhar a potência da obra, a sua atualização que foi, paulatinamente, incorporada nos ditos científicos do hoje.

Ao iniciar seu texto $O$ que é um autor, Foucault se justifica usando sua clássica obra $A s$ palavras e as coisas, para dizer que não se tratava de esmiuçar incessantemente as ideias e obras de Buffon ou Marx. Tratava-se, isto sim, de tensionar, de pensar sobre elas, de entender determinados modos como os autores conceituavam suas ideias.

[...] o problema para mim não era descrever Buffon ou Marx, nem reproduzir o que eles disseram ou quiseram dizer: eu buscava simplesmente encontrar as regras através das quais eles formaram um certo número de conceitos ou de contextos teóricos que se podem encontrar em seus textos (FOUCAULT, 2001, p. 266).

Seguindo as trilhas de Foucault, gostaria de me afastar de uma análise que trouxesse o valor expressivo dos conceitos de Bacon e Descartes. Envolta com a inquietante discussão a respeito da função-autor, tratarei desses materiais como uma apropriação de nossa cultura, antropocêntrica e científica, não me importando com seu papel de fundador originário do discurso. Assim é que tomo os clássicos Novum organum e $O$ discurso do método como duas transdiscursividades.

O desejo é dar a ver o discurso da ciência moderna, especialmente a partir dos dois clássicos sob análise, como uma das condições de possibilidade para emergência da crise ambiental contemporânea. Na busca pelo domínio da natureza, através do progresso da ciência, Bacon e Descartes a pensaram e desejaram seu domínio, não medindo esforços para isso.

[...] somos herdeiros diretos das experiências que marcaram as relações entre sociedade e natureza de nossos predecessores e, da mesma forma, deixaremos para a posteridade nosso legado, aquilo que pudermos construir em nossa existência individual e coletiva. Essa herança seria, por assim dizer, como a língua, a qual já existe quando nascemos, na qual aprendemos a nos expressar e por meio da qual ordenamos nossa experiência do mundo e da natureza (CARVALHO, 2008, p. 104). 
Nossa herança moderna se produz de tal modo que, muitas vezes, nem nos damos conta da presença dela. Na busca pelo progresso do mundo e melhoria de suas condições de vida, o homem moderno foi objetificando a natureza e tornando-a espaço de sua apropriação. Se mirarmos rapidamente alguns dos grandes desastres ambientais, vimos isso com precisão. O acidente nuclear em Chernobyl em 1986 levou à morte quase 80 mil pessoas, estimando uma radiação nuclear cem vezes maior que as bombas de Hiroshima e Nagasaki. O derretimento de petróleo na embarcação Exxon Valdez, em 1989, foi uma maré negra de 36 mil toneladas de petróleo, afetando a fauna e a atividade de pesca, além de matar 250 mil aves. O derrame tóxico de alumínio em Ajka cobriu de um mar vermelho em 2010 a cidade da Hungria, afetando milhares de vítimas devido ao alcance da substância. $\mathrm{O}$ acidente nuclear de Fukushima ocorreu em 2011, devido ao derretimento de três reatores nucleares, evacuando da área 300 mil pessoas; seus efeitos foram comparados ao acidente de Chernobyl, alcançando também o nível 7 da Escala Internacional de Acidentes Nucleares. O rompimento da barragem de Mariana, em 2015 devastou o local e, cobrindo o município de lama, contaminou o Rio Gualaxo, acabando com diversos ecossistemas.

Uma indústria nuclear soviética; um navio petroleiro de 300 metros de comprimento; uma indústria japonesa; uma fábrica de alumínio ao oeste de Budapeste e um empreendimento conjunto de duas empresas de mineração no Brasil. O que esses cinco eventos têm em comum? Um desejo de desbravamento da natureza, agora, atualizado talvez em marcas de uma tecnociência, que acaba por tomar outros rumos, de destruição, de estrondos, de desastres ambientais. O que quero colocar em destaque é que a crise ambiental vem assumindo formas até então não imaginadas pelo homem moderno. A busca pelo progresso, os contornos cada vez mais acelerados do capitalismo, a exploração da natureza assumem novos traçados, talvez nem mesmo imaginados por Bacon e Descartes. É aí que, com nossa atualidade, e com outros acontecimentos, atravessamentos e dispositivos, seus ditos não param de ser incessantemente repetidos, revisados e atualizados por nós.

Não se trata de dizer que somente Bacon e Descartes nos deixaram esse legado. Longe disso, o que quero é olhar com cuidado um discurso que foi muito mais além do que seus próprios autores. Os frutos gerados na modernidade são atualizados em tempos contemporâneos. É nesse sentido que a pergunta foucaultiana tem total aderência a esse trabalho: "que importa quem fala?" (FOUCAULT, 2001, p. 264). Não se trata de Bacon ou de Descartes. Trata-se deles na medida em que entendemos seus ditos como tramados em uma rede discursiva muito mais ampla que o próprio autor. Uma rede que se fabrica atualizando nossos modos de existir. Uma rede que nos ensina, atualizada que é, a objetificar a natureza, agora, talvez, com uma nova aura, a da preocupação com o futuro. Não mais o cogito descarteano, por assim dizer, mas novos "[...] modos de existência, de circulação e de funcionamentos de certos discursos no interior de uma sociedade" (FOUCAULT, 2001, p. 274).

É assim que a crença desenfreada que fez nascer a ciência moderna no século XVII, ou o desejo de ordem e pureza, ou ainda o ímpeto humano de saber cada vez mais para dominar encontram ressonâncias em tempos atuais. Sem dúvida, as críticas e desacordos com esses autores povoam diferentes campos de saber da ciência hoje em dia - a Educação é um deles. No entanto, é justo esse desacordo, esses limites do texto moderno, com seus recortes que o faz se atualizar. Com isso, os nomes de Bacon ou Descartes se veem apagados. Não se trata deles, em específico, mas de seus ditos que se veem repetidos, recortados, caracterizados 
em uma outra sociedade. Nas palavras de Foucault (2001, p. 274): “O nome do autor não está localizado no estado civil dos homens, não está localizado na ficção da obra, mas na ruptura que instaura um certo grupo de discursos e seu modo singular de ser”.

A função-autor opera na medida em que a atualização se faz. Daí a fabricação de outros discursos, guardando relação com o rosto, já apagado, de seu autor. Novos discursos, atravessados por modos de pensar a ciência moderna, mas já não mais as enunciações que lhe deram origem. Diante disso, parece importante relembrar algumas enunciações de Bacon e Descartes, no sentido de pensar como seus estudos podem ser tomados como uma das condições de possibilidade para emergência da crise ambiental. Afinal, neles estava seu objetivo com a criação da ciência, desbravar da natureza.

\section{As heranças modernas e sua atualidade}

O homem, como ser capaz de nomear e classificar as coisas naturais encontra-se, agora, aliado à ciência, com o cetro do mundo (NIETZSCHE, 2002). Um enquadramento do mundo natural, trazendo a ordem e a pureza para a necessária civilidade, distanciando-se de tudo que poderia trazer a possibilidade de barbárie e desordem. A natureza, enquanto espaço desconhecido ou ainda um espaço pouco explorado pelo homem, remete a necessidade de se desenvolver saberes para que se possa conhecer e dominar. Daí a máxima baconiana de "Saber é poder".

Só então poderemos dizer ter colocado nas mãos dos homens, como justo e fiel tutor, as suas próprias fortunas, estando o intelecto emancipado e, por assim dizer, liberto da menoridade; daí, como necessária, segue-se a reforma do estado da humanidade, bem como a ampliação do seu poder sobre a natureza. (BACON, 1979, p. 230).

Muitas transformações culturais, sociais, econômicas, religiosas, políticas ocorreram no período chamado Renascimento. Um conflito entre um mundo nascente e um mundo já desgastado parece trazer outros tons e olhares para este tempo. Teorias do geocentrismo para o heliocentrismo; advento do humanismo; engrandecimento do homem; razão como elemento fundamental do humano; novos modos de fazer ciência são alguns dos acontecimentos que fazem nascer uma outra ordem para o mundo ocidental.

Desfazendo de todo e qualquer saber dos gregos, Bacon (1979) dá a seu livro o nome Novum Organum para definir novos modos de se chegar ao verdadeiro conhecimento. Querendo superar o silogismo aristotélico, o cientista desqualifica a filosofia antiga, dizendo que os gregos investigam tagarelando (BACON, 1979). Era preciso um método mais seguro, mais sólido para que o domínio da natureza pudesse ser efetivado. Ela precisa ser esquadrinhada, e se ciência é poder, é preciso conhecer, verificar, controlar o mundo natural.

Mas aqueles dentre os mortais, mais animados e interessados, não no uso presente das descobertas já feitas, mas em ir mais além; que estejam preocupados, não com a vitória sobre os adversários por meio de argumentos, mas na vitória sobre a natureza, pela ação (BACON, 1979, p. 7, grifo nosso). 
$\mathrm{Na}$ busca pela Grande Instauração - de onde se poderia ter "a vitória sobre a natureza" - Bacon investe em construir o método indutivo, partindo de fatos concretos, criam-se formas gerais que contribuem para os domínios da técnica e da ciência. E é aqui que o homem, longe de ser a imagem e semelhança de Deus, é "[...] ministro e intérprete da natureza" (BACON, 1979, p. 13).

Desacralizando o mundo, Descartes nos ensina que o homem moderno precisou perder o medo de tocá-lo, de conhecê-lo. É somente a partir da sua dúvida metódica, do seu desejo por racionalizar o mundo e explorar que é possível conhecer. Assim é que o homem concebeu o mundo como matéria inerte. O sujeito racional de Descartes é aquele que, com o bom uso da razão e livre de suas paixões, consegue, seguindo as regras metódicas, chegar a pensar os problemas que lhe aparecem. E consegue resolvê-los! Por isso, vemos em seu Discurso do método o destaque à matemática. Para ele há um acordo fundamental entre as leis da natureza e as leis matemáticas. É assim que o conhecer se dá pela ação e se torna a própria dominação da coisa. O homem, entendendo o método, conseguirá desbravar os mistérios da natureza.

[...] é possível chegar a conhecimentos que sejam muito úteis à vida, e que, em lugar dessa filosofia especulativa que se ensina nas escolas, é possível encontrar-se uma outra prática mediante a qual, conhecendo a força e as ações do fogo, da água, do ar, dos astros, dos céus e de todos os outros corpos que nos cercam, tão claramente como conhecemos os vários ofícios de nossos artífices, poderíamos utilizá-los da mesma forma em todos os usos para os quais são próprios, e assim nos tornar como senhores e possuidores da natureza (DESCARTES, 1996, p. 116. grifo nosso).

Nesse momento histórico a inversão tão desejada se constitui aqui: a natureza agora já não é aquela que controla os homens, agora se trata do seu inverso: o homem como "senhor e possuidor" da mesma. Consolida-se, com o advento da ciência moderna, o desejo pela ordem e pela criação de um método seguro, que garantisse a chegada ao conhecimento e, justo por isso, o domínio humano sobre a natureza. Uma ciência enquanto projeto universal que, abandonando a tradição e assumindo a dúvida metódica, levaria a humanidade à chegada da verdade clara e precisa. Descartando os sentidos, inexatos e confusos, deveríamos nos persuadir "[...] pela evidência de nossa razão" (DESCARTES, 1996, p. 96).

E é com esse objetivo que Descartes cria o seu método cartesiano. É necessário saber o caminho a trilhar para chegar à verdade e seu caminho é um único: a ciência. Daí porque cria seu método no desejo de apresentar "[...] regras certas e fáceis, graças às quais todos os que as observam exatamente jamais tomarão como verdadeiro aquilo que é falso" (DESCARTES, 1996, p. 81). Com sua primeira grande verdade, "Penso, logo existo", o francês nos ensina que mesmo duvidando de tudo, não podemos cair num ceticismo absoluto. É então que, pensando e examinando as coisas e os fenômenos, entendo que existo.

A ciência, conhecendo o que é desconhecido, coisifica o objeto. Através de nossos avanços científicos, fomos conhecendo cada vez mais daquilo que era divinizado na Grécia Antiga. A natureza, agora, é tomada como objeto que o homem moderno deve conhecer para dominar, para governar e criar conhecimentos que possam servir para o seu benefício próprio. É em nome da ciência que justificamos todas as ações para o domínio e exploração da natureza. Um 
sistema ordenado que cabe ao homem entender e criar condições de exploração. Um imenso relógio que se repete numa constante. É preciso solidificar e matematizar a natureza. Não basta as sensações humanas. O homem com suas qualidades sensitivas é expurgado de um espaço que precisa entender a máquina do mundo natural através de sua matematização. Matéria bruta que exige tratamento racional.

Vê-se, tanto em Bacon quanto em Descartes uma separação dual, entre homem e natureza. Humanidade e natureza são dois sistemas antagônicos, cabendo ao primeiro conhecer, para desbravar o segundo. Para a visão mecânica de Bacon, e, cartesiana de Descartes é fundamental que essa dualidade exista. O homem é cogito descarteano e a natureza, seu objeto a ser desbravado.

Com os ensinamentos científicos de Bacon e Descartes, a natureza se torna outra coisa, muito diferente dos modos sentidos e vividos em tempos anteriores ${ }^{2}$. Depois das fabricações científicas modernas, o modo como nós, humanos contemporâneos, a sentimos já é outro, atravessado que está por novas verdades e criações. Daí porque a enxergarmos descolada de nós, olhando para o mundo enquanto objeto natural passível de desbravamento e de compreensão racional. Um independente recurso a ser consumido, em prol do homem, da vida e do mundo moderno. De um lado, mundo físico, de outro, mundo humano, científico e racional. Retiramos da natureza qualquer possibilidade histórica e cultural que pudesse ser pensada. Mecânica, numérica e quantificável a tornamos objeto. Frio, passível de intervenção para domínio humano. Como lugar do impuro, imperfeito e desordenado, esse objeto merece nossa atenção para ser, com o auxílio da técnica e da ciência, remodelado para o uso da humanidade. É dessa vontade de ordem, fruto da Modernidade, que se investiu inúmeros esforços para objetificação da natureza.

Keith Thomas (THOMAS, 1988) nos ajuda a entender os modos como a ordenação moderna e o seu desejo de domínio do século XVII olhavam para a terra cultivada como aquela que era boa e bonita, aquela que suas montanhas e mata fechada eram limpas e ordenadas pelo homem, expurgando uma natureza selvagem, desconhecida e, por isso mesmo, representando um perigo para humanidade. O saber científico é medido a partir do domínio da natureza (águas, rios, tempestades,...). E seu investimento agora é para classificar e nomear as coisas naturais. Não basta contemplar a flor e sentir seu perfume. Isso já não tem sentido em um mundo regido pelos ditames científicos. É preciso classificar, nomear os “encantos" da flor, definir suas características, sua utilidade para vida humana. "A prática de plantar cereais ou vegetais em linha reta não era apenas um modo eficiente de aproveitar espaços, mas também representava um modo agradável de impor a ordem humana ao mundo natural desordenado" (CARVALHO, 2008, p. 96).

O avanço do processo civilizador moderno - valoração do modelo urbano - traz consigo a relação quase direta entre civilidade e cultura, razão e progresso. Em contrapartida, está em sintonia a natureza e a selvageria, a barbárie e a feiura. Ameaçando a civilidade,

\footnotetext{
${ }^{2}$ Para além da dominação da natureza, criamos outros esquadrinhamentos, demarcando que ela necessita de nossa proteção. Esse artigo tratará sobre isso na sequência. 
os ambientes naturais são tomados como desordenados e, por isso, repudiados pelo homem moderno. É daí que a natureza é vista como espaço de domínio e lugar de onde provém o suprimento para as necessidades humanas.

Encarando a natureza desse modo, o homem ocupa papel central: é ele, a partir do empirismo e do racionalismo, que poderá dominar o objeto de estudos, no caso, a natureza. Aí vemos um marco que estamos longe de nos afastar. Ao homem moderno cabe, a partir do sucesso científico, mirar o futuro e definir ações possíveis.

Cabe dizer que esse é um dos muitos discursos que se fabrica na ciência. Não se trata de dizer que todo esse grande saber é feito a partir da crença desenfreada e da relação direta ciência - sucesso - futuro. Evidentemente, outros olhares, modificações no pensamento científico foram sendo tramados ao longo desses quatro séculos. Não quero desconsiderar aqui, as grandes discussões travadas em diferentes campos de conhecimento que tensionaram as verdades científicas, trazendo a dúvida e a relatividade desse saber mais duro do século XVII. Estão aí inúmeros estudos que nos fazem olhar para a ciência de um modo mais provocativo. Os autores-intercessores desse estudo ajudam nesse movimento, por exemplo. Além deles, basta vermos as discussões trazidas na década de 1960 e 1970 do século XX por Thomas Kuhn e Paul Feyerabend, chamados, ainda hoje, de "inimigos da ciência". No entanto, na continuidade do texto, quero dar a ver uma atualização do poder científico baconiano/descarteano. Gostaria de deixar claro que não limito ou unifico os discursos científicos somente a partir dos dois exemplares que tratarei a seguir, desse modo estaria sendo totalmente contrária aos estudos que embasam meu trabalho. Resta evidente, que algumas das enunciações que compuseram esses movimentos, atualizam o desejo de ordem e descobrimento da verdade através da ciência. O que quero é trazer elementos que podem nos mostrar a reativação de uma máxima da Modernidade: a ciência como progresso, um saber que pode, agora, nos explicar as coisas do mundo e trazer a melhoria de nossas condições de vida. Como nos lembra Stengers (2002, p. 83): "A imagem do progresso é poderosa".

A partir de dois episódios atuais, gostaria de pôr em destaque a aposta na ciência como aquela que nos ajudará a enfrentar os problemas do futuro. A Nova Atlântica de Bacon ecoa em tempos contemporâneos, encarando a ciência como saber legítimo para um futuro de maior bem-estar para humanidade frente aos problemas ambientais que estamos vivendo. $\mathrm{O}$ objetivo aqui é olhar com cuidado e sutileza os modos como a acionamos enquanto aquela que pode - e deve! - criar condições para resolução das mazelas sociais.

O primeiro episódio refere-se à Marcha pela Ciência, que levou milhões de cientistas e simpatizantes às ruas em 22 de abril de 2017 em dezenas de países do mundo inteiro. Querendo contrapor ao crescente "descaso com o conhecimento baseado em evidências" (MARCHA..., 2017b), a Marcha buscava realizar uma celebração à ciência. Tratando de dar visibilidade aos cortes orçamentários em pesquisa, desenvolvimento e tecnologia em vários países, o evento uniu milhares de cientistas para pedir "mais visibilidade e credibilidade à ciência" (MARCHA..., 2017a). Tendo como um dos seus objetivos "celebrar su pasión por la ciencia" (BERNARDO, 2017), o evento foi impulsionado devido ao ceticismo de Donald Trump, atual presidente dos Estados Unidos, a respeito da mudança climática. Diante de tamanha indignação da comunidade científica, a escolha do dia da Marcha, não foi sem razão. Protestando sobre a necessidade da ciência com seu papel vital para a democracia, o Dia Mundial da Terra foi a data escolhida para o protesto. 
Vale um adendo a essa discussão. Sem dúvida os atuais cortes financeiros ao desenvolvimento científico vêm preocupando a todos nós, pesquisadores dos diferentes campos da ciência. A limitar-me apenas ao campo das questões ambientais, ressalto a necessidade de investigações sérias e comprometidas com a situação da crise ambiental que vimos experienciado através do aquecimento global, por exemplo.

Ocorre que na divulgação mais ampla à sociedade de modo geral, a Marcha pela Ciência nos chega a partir de uma visão marcada por uma atualização baconiana de tamanha repercussão em cenário nacional e internacional. "Sem ciência não existe desenvolvimento; [...] Se perdermos nossos cientistas, como será possível desenvolver o país?” (MARCHA..., 2017a). Vimos aí um desejo de progresso a partir de enunciações que trazem o futuro como algo a ser mirado. E mirado de modo muito particular: a partir do saber da ciência que pode, enfim, trazer o desenvolvimento e progresso da humanidade. "Nós amamos a ciência" ou "Sem ciência não há futuro" foram slogans de cartazes que povoaram as ruas do mundo inteiro neste ano. Poderia dizer que enunciações como essas nos remetem ao desejo moderno de criar algo que pudesse, agora, nos tirar do mundo das sensações, que nada ajudam a pensar racionalmente sobre as coisas da vida. A crença na ciência moderna encontra-se, frente a frente, com os ímpetos atuais de fazer da ciência. O saber que nos possibilitará melhores dias, melhores respostas e uma solução para a devastação da Terra. É desse modo que a ciência continua sendo quase um dogma para nós. Algo quase intocável, inabalável. Saber que, por chegar à verdade, nos concede previsões, definições, determinações que levarão a uma suposta vida melhor.

O segundo episódio refere-se a um embate de forças entre uma centena de renomados cientistas, ganhadores de prêmios Nobel e a Organização Não-Governamental Greenpace a respeito do uso de alimentos geneticamente modificados. Em junho de 2016, cento e nove cientistas solicitam ao movimento ambientalista que "abandonem sua campanha contra os cultivos geneticamente modificados, em geral, e o arroz dourado, em particular" (WHY..., 2017, tradução nossa). De um lado, encontram-se renomados cientistas, argumentando, através de suas pesquisas, que não há provas a respeito de algum mal causado pela ingestão de alimentos transgênicos; de outro, está o Greenpace, questionando algo quase inabalável: o prestigioso conhecimento científico.

Segundo a Greenpace, há soluções mais eficazes e não agressivas ao meio ambiente do que a utilização de alimentos transgênicos, como é o caso do polêmico arroz dourado (GREENPEACE, 2015). A agricultura ecológica pode oferecer alimentos para combater a desnutrição e, ainda, pensar nos cuidados com o meio ambiente. Atacando a Greenpeace por criticar o cultivo de alimentos geneticamente modificados, os laureados dizem que o movimento ambientalista faz um crime contra a humanidade: “[...] É preciso deter a oposição baseada em emoções e dogmas, em contradição com os dados" (WHY..., 2017, tradução nossa). E uma vez mais o domínio da ciência se vê presente: "Nós somos cientistas. Nós entendemos a lógica da ciência. É fácil perceber que o que o Greenpeace está fazendo é danoso e anticientífico”, diz Richard Roberts, prêmio Nobel de Fisiologia ou Medicina (1993) junto com Philip Allen Sharp (109 vencedores..., 2016).

A transdiscursividade da ciência moderna se vê ementada nos argumentos postulados pelos laureados. Se Bacon e Descartes nos ajudaram a compor um novo mundo, cientistas contemporâneos os chamam em auxílio, atualizando suas lições. A ciência se produz como regime de verdade ainda em tempos contemporâneos. Por que tomamos os cientistas como "[...] os 
únicos representantes legítimos das coisas” (STENGERS, 2002, p. 191)? Podemos entendê-la como uma verdade inventada e fabricada nas tramas de um solo positivo, a episteme moderna. É daí que emergem saberes imiscuídos nesta ordenação histórica. É dizer, produzidos no seio dessa episteme, estamos amarrado a ela e fabricando modos de vida que nos constituem e determinam.

Ao apresentar uma taxinomia dos animais em uma enciclopédia chinesa - completamente estranha aos nossos modos de classificação dos seres vivos -, Foucault (2002, p. ix) nos lança a inquietante pergunta: "Que coisa pois é impossível pensar e de que impossibilidade se trata?". Trata-se do solo positivo que nos abriga. A episteme permite-nos entender os jogos de forças e limitações que determinam um dado discurso. Ao olhar exemplares como esses dois episódios trazidos aqui, vimos ainda a crença na ciência, filhos que somos da Modernidade.

Sabemos que a epistemologia subordina a verdade à ciência. A ciência é o lugar específico da verdade que lhe seria exterior, pois só seus procedimentos são capazes de produzi-la; a questão da verdade se reduz a dos critérios do conhecimento verdadeiro, critérios esses definidos pela ciência em sua atualidade (MACHADO, 1988, p.184).

Com isso, o abrigo desse solo positivo nos permite dizer coisas, agir em nome daquilo que nos é dado como verdadeiro. E a verdade é assumida aqui como relações de força, saberes que se enfrentam, sendo alguns acendidos a condições legítimas e necessárias (NIETZSCHE, 2008). Com o racionalismo e o empirismo, vimos nascer a verdade da ciência moderna. Hoje, vimos a atualização de seus ditos para, novamente com a ciência, fazermos algo para o bem da humanidade, agora no desejo de vê-la salvando a Terra, chamamento que parece muito evidente com o dia escolhido para a Marcha da Ciência, por exemplo.

Agora, é necessário cuidar daquilo que foi o objeto de domínio moderno. É preciso pensar nos modos como usurpamos a natureza e, para isso, a ciência cria diferentes estratégias de gerenciamento sobre nossas ações: estatísticas de fim de mundo, pesquisas de previsão do futuro, etc. Miremos então que posição assume esse humano: o que cabe ao sujeito contemporâneo?

É com Bacon e Descartes que o homem assume uma posição central no mundo. Evidentemente marcas desse humanismo já estão no velho testamento, quando somos convocados a ser "a imagem e semelhança de Deus", dominando as coisas terrestres. No entanto, é com o projeto inicial da Modernidade que o homem adquire a posição de destaque, sem mais a presença de um grande Deus criador, ou ainda, a necessidade de sua subserviência a Ele. Agora, é o humano quem, com todas as suas forças, sua determinação e saber científico, conseguirá, enfim, dominar o mundo. Uma nova ética se consolida: a ética antropocêntrica. As explicações religiosas já não dão conta sobre os acontecimentos terrestres. É este humano que poderá, a partir do crivo científico, explicar as coisas do mundo. E desde já, o lugar de posição assumido aqui é outro, o centro do mundo.

Em tempos contemporâneos, assumindo uma posição de destaque, o homem parece assumir também mais uma grande responsabilidade que, antes, não o era exigido. Se em Bacon e Descartes, ele precisa desbravar e dominar a natureza, agora, a ele cabe também ocupar o lugar de sujeito que, com o bom uso da ciência, poderá salvar aquilo que vem dando sinais de colapso: a natureza. É a partir dele e com ele que a natureza poderá sobreviver. 
Marcas desse entendimento moderno participam e convocam os nossos modos de existir e conviver com a natureza em tempos contemporâneos. As diferentes indicações de ações para nossas vidas cotidianas perante a natureza, a suposta solução a partir da sustentabilidade são exemplos disso. Separe o lixo, plante uma árvore, use transporte coletivo, consuma menos, use sacolas retornáveis são potentes enunciações que vão nos educando para outras práticas mais sustentáveis, mais verdes, mais preocupadas com a continuidade da vida na Terra. Essas indicações são dadas em diferentes meios de comunicação, na escola, na família, em lugares que circulamos. Tais indicações, muitas vezes, vêm com um amontoado de ditos que nos ensinam o quanto nós, seres humanos, estamos acabando com o planeta. Quando esses materiais anunciam, de modo catastrófico e terrorista, o fim do mundo, tais afirmativas estão atravessadas tanto pela inculcação da culpa do ser humano como por sua responsabilidade para reverter a situação dos desastres ambientais que vivemos. A partir de estatísticas, prospectivas e causa-efeito trazidos pela voz da ciência parece que não nos cabe outra posição senão essa: se fizermos a nossa parte, salvaremos o planeta!

Chamo a atenção para que percebamos de onde advêm esses potentes ditos. Com o homem da ciência, desbravamos o mundo; a partir de suas pesquisas e estudos descobrimos o provável futuro, nada tranquilo, que teremos que enfrentar devido às agressões sofridas pela natureza. Aquela posição humana de destaque, que dá condições para o nascimento da ciência, nos ensina, hoje, que é preciso pensar no futuro e agir para termos melhores dias. E essa mesma posição nos coloca, mais uma vez, num grande lugar de destaque: podemos reverter a situação. É aqui que vimos de modo muito mais enfático a junção daquilo que já nos anunciava Foucault (2002a): o campo epistemológico, com os saberes expertos da ciência, nos diz o que está por ocorrer e o campo político nos ensina como devemos agir para reverter tal situação. Inventa-se o saber da ciência e, junto com ele, conectam-se técnicas de governo no desejo de definir modos de vida.

Trata-se de enxergar os desastres ambientais e tomarmos partido a favor ou contra (d)a natureza. Seja como destruidor do ambiente, desejo moderno encarnado no domínio e exploração da natureza; seja, agora, através do duplo lugar assumido por ele em tempos atuais, o de salvação do Planeta. $O$ antropocentrismo permanece como condição indispensável para a manutenção do conceito moderno de natureza.

Resta ainda uma outra reativação discursiva: a posição da natureza. Se antes ela era tomada como objeto a ser desbravado, em tempos contemporâneos vimos um distanciado disso, em alguma medida: é preciso proteger a natureza. Vimos frequentemente as manchetes de jornais e revistas, a escola atuando para educar os alunos para um cuidado com o meio ambiente, os filmes de animação sob o tema da preservação ambiental, as histórias em quadrinhos desejando a velha e boa natureza, a literatura infantil ensinando como preservar a água, o solo e os animais, etc (GUIMARÃES, 2012; HENNING, 2017; WORTMANN, 2004).

Ainda que rapidamente pudéssemos nos convencer de uma suposta inversão - de desbravamento para a proteção da natureza -, vale uma atenção redobrada de nossa parte: a natureza parece ser mirada de outra forma em tempos contemporâneos; no entanto, ela é ainda o objeto da ciência. Humano e natureza continuam apartados. Está aí mais uma das condições de possibilidade para emergência da crise ambiental: uma cisão cunhada especialmente pela modernidade que parece impossível de pensarmos diferente. A natureza permanecesse sendo objetificada por nós. 
Dou visibilidade aqui para as Unidades de Conservação (UC), espaços destinados a proteger os recursos naturais. Um antídoto contra a devastação que o humano pode causar à natureza. Conhecemos, é certo, os parques de Yosemite (1864) e Yeloowstone (1874), criações do século XIX. No entanto, com esses inventos não existia ainda a ideia de áreas protegidas, no intuito de resguardar a natureza da civilização. Isso só ocorre a partir do século XX. E é nesse momento que vemos eclodir diferentes unidades de conservação. Basta ver a Lei 9.285/2000, instituindo a criação do Sistema Nacional de Conservação da Natureza (BRASIL, 2000). Uma junção entre Federação, Estados e Municípios brasileiros para conservar os ecossistemas e a biodiversidade do país. Em território nacional brasileiro temos quase 800 unidades de conservação (BRASIL, 2017). Com seus diferentes nomes - Parque Nacional, Áreas de Proteção Ambiental, Reserva Ecológica e etc - as UC's são territórios delimitados que somente alguns têm acesso, buscando proteger a natureza. Ditames científicos, políticos e culturais vão definindo os espaços, demarcando territórios, se apropriando de determinados lugares e dizendo como, agora, devemos preservar a natureza. Um lugar de proteção criado para contemplarmos a natureza, desde que aceitemos as regras do jogo. Um lugar de ordenamento e investigação científica.

A criação de lugares e a definição das operações são lentamente fixadas no corpo do território, primeiro como uma prática, depois como procedimento, formando o âmbito em que a ecologia, pela biologia da conservação, surgirá como o domínio de conhecimento apto a estabelecer os modos de operação a partir dessas práticas já fixadas, isto é, o problema que se põe não é a destruição da natureza, mas de como operar sobre ela (GODOY, 2000, p. 132).

É sobre a natureza que continuamos criando nossas melhores explicações científicas. Agora se identifica, se classifica a natureza, num lugar resguardado para irmos e sentirmos o ar puro, os animais exóticos, as flores e os campos verdejantes. Criamos lugares de natureza e definimos os modos como devemos nos comportar frente a ela. E quando quisermos estar entre os elementos naturais, vamos até eles... exteriorizamos aquilo que não nos pertence, aquilo que não cabe em nós e, justo por seus mistérios e nossa falta de domínio, precisamos aprisionar, conhecer para dominar. Agora, com um novo elemento, a busca pela sua proteção.

Paradoxalmente, a natureza dos lugares criados - como as UC's - são espaços que conservando, exploram-na. O campo científico define, a partir do saber dos expertos, ecologia, biologia, educação ambiental, os lugares que serão as áreas de proteção. E a partir daí cria-se uma rede de espaços para esmiuçá-la, defini-la, descrevê-la. Explora-se de maneira razoável, criando experiências para o domínio do conhecimento, define-se até onde a exploração pode ir, pois agora, resta evidente, a natureza precisa de proteção.

Bacon e Descartes nos ensinaram, seja pelo empirismo, seja pelo racionalismo, os modos como deveríamos explorar e dominar a natureza, através do bom uso da razão. Posicionando-a como objeto a ser desbravado, a natureza, assume esse lugar. E nós estamos fora dela, observando-a, calculando-a, racionalizando-a para, enfim, criar saberes sobre esse objeto. Essa cisão entra $a$ natureza e $a$ humanidade, nos coloca do lado de fora. Agora somos aqueles que, imbuídos do saber científico, conseguimos, enfim, entendê-la, discutir sobre seus 
encantos, seus mistérios e suas belezas. A nós cabe essa tarefa: descrevê-la. E para isso, precisamos nos posicionar longe, exteriormente. A luta científica pelo controle absoluto da natureza cria a dualidade, empurrando-a para fora do nosso mundo. Ela continua sendo, objeto passivo nas mãos do homem da ciência.

Resta evidente que os modos de enxergá-la foram modificados, ora como passiva, a espera do humano para dominá-la; ora como enfurecida, a partir das catástrofes ambientais que nos acomete; ora como aquela que necessita de cuidado e proteção humana. Sem dúvida, distintos acontecimentos foram criando modificações no cenário inicial da Modernidade. Os desastres ambientais, desde meados do século XX, por exemplo, fizeram com que o mundo repensasse o desejo desenfreado de exploração da natureza. A ciência começava a ver seu rosto destruído, ouvia críticas a respeito do seu uso, indignações devido à forma como os humanos faziam uso dela. Isso cria uma inversão nos modos como enxergamos a natureza. Frente aos totalitarismos científicos, atrelados ao progresso do capitalismo, a natureza, agora, torna-se algo a ser preservado.

Mirando alguns elementos históricos que demarquei nesse texto, gostaria de potencializar em nós, estudiosos e pesquisadores, a importância de compreender os fundamentos da Educação Ambiental. Concordando com Carvalho, Farias e Pereira (2011) e ainda com Grün (2006) as bases históricas da ciência moderna podem contribuir para pensarmos na importância da Educação Ambiental. Uma EA que passe pelo exercício da urgência de pensar a atualidade, de exercer a crítica sobre nossa história. É na potência do pensamento, estendendo nossas heranças (STENGERS, 2005) que podemos criar outras educações ambientais que passem pelo exercício da problematização dos nossos modos de existir e conviver com a natureza em tempos atuais.

Da Modernidade até nosso momento contemporâneo, ecoa em nós o murmúrio da poeira dos livros. O campo de estudos da Educação Ambiental não pode ficar indiferente às nossas marcas históricas. O plano cartesiano foi traçado, e nós, sujeitos desse tempo, parecemos ter sido fiéis - no sentido da função-autor de Foucault - na atualização sempre e uma vez mais, da cisão entre nós e ela, entre humanos e natureza. Seja dominando, seja preservando, Bacon e Descartes nos deixaram uma herança que está longe ter caducado.

\section{Considerações Finais}

O projeto inicial da Modernidade deixa em nós diferentes marcas e fraturas. $\mathrm{O}$ artigo aqui escrito pretendeu evidenciar algumas atualizações discursivas de tal projeto. A ciência como o saber autorizado a desbravar o mundo; o homem em sua dupla posição, de responsável por conhecer a natureza e salvá-la e a natureza como objeto de domínio moderno, seja pela exploração, seja pela preservação foram os modos como busquei evidenciar a repetição, o eco, o eterno retorno, sempre diferente dos dois autores, já borrados da era dos setecentos.

Com o projeto de exploração da natureza e os caminhos, minuciosamente traçados por Bacon e Descartes para nos ensinar a alcançar esse objetivo, tivemos aí uma das condições de possibilidade para emergência da crise ambiental. Sem dúvida, essa é apenas uma das muitas condições possíveis de serem analisadas. Ao retornarmos aos ditos baconianos e descarteanos repetidas vezes, fomos criando fraturas e refinamentos nos modos como dominamos aquela 
que foi e ainda é nosso objeto de saber: a natureza. Inventamos diferentes modos de descrevê-la. A cada nova invenção científica, o desbravamento foi desgastando-a e criando cada vez mais problemas ambientais que apresentam sua pujança em tempos contemporâneos. As atualizações discursivas nos dão a ver a repetição, contínua e sempre reinventada, de tal desejo de domínio.

Assim é que cabe a pergunta: se esses murmúrios ainda ecoam em nós, o que cabe ao campo da Educação Ambiental? Resistirmos ao presente e ensinarmos nossos alunos a também resistir talvez possa ser uma das muitas possibilidades que temos. É com Stengers que vejo a importância de estendermos nossas heranças e, desde aí, tensionarmos a nossa atualidade.

De fato, penso que nós não podemos renunciar à referência ao progresso, porque não temos escolha; no momento em que a questão se coloca para nós, somos definidos como herdeiros desta referência, livres talvez para redefini-la, mas não para anulá-la. E o interesse de nós sabemos que não podemos mais acreditar passa a ser então o problema que esta frase anuncia. Saber que não se pode mais acreditar não significa desembaraçarse da herança - nem vista, nem conhecida, seria um mal-entendido, ou um erro -, mas aprender a estendê-la de outro modo (STENGERS, 2002, p. 183, grifo nosso).

Como estender nossa herança? Parece aí encontrarmos aquilo que Foucault (1995) e Deleuze (1988) nos provocavam: resistindo ao presente. Resistindo, criamos. Inventamos coisas, vidas e lugares. Resistir ao estabelecido pela Modernidade, a objetificação do mundo. Sem dúvida, levar ao limite nosso pensamento não é nada fácil... pensar em ações políticas que levem o campo da Educação Ambiental para além da necessária resolução de um problema me parece ser um dos desafios de nosso campo de saber.

Com isso, não quero dizer que não devamos pensar sobre a crise. Sim, essa é uma de nossas responsabilidades. Pensar no limite do nosso pensamento a crise que estamos vivenciando faz parte da Educação Ambiental e talvez aí esteja um dos seus possíveis efeitos nos sujeitos contemporâneos. Mas pensar sobre a crise não nos leva a ter que resolver um problema que vimos constituindo a mais de quatro séculos.

No fluxo de acontecimentos marcados pelos desastres ambientais nosso campo de saber se gestou. "A educação, então, deveria responder a este quadro de perplexidade educando os cidadãos para o meio ambiente. Assim, formou-se hoje uma forte convicção no meio acadêmico-científico e político de que precisamos de uma educação ambiental' (GRÜN, 1996, p. 20, grifo do autor). Filha de um sério problema, a EA parece assumir a responsabilidade de criar soluções para nossa preocupação planetária. Um campo que parece se apresentar como aquele que busca, incansavelmente, a conquista da tão sonhada consciência ambiental. Continuamos esperando da EA a conscientização dos sujeitos a respeito das catástrofes ambientais, ensinando modos de se comportar no meio ambiente, de como cuidar do planeta, de como termos um futuro melhor, etc. "Atualmente podemos assistir a uma rápida, e às vezes, desesperada procura por soluções e respostas aos problemas ambientais no âmbito da educação" (GRÜN, 1996 , p. 20). 
E se a EA pudesse partir de outro lugar? Não do lugar da solução, mas do lugar do encontro, da potência do pensamento. Se ela pudesse aceitar o desafio de resistir ao presente? $\mathrm{E}$ se ela funcionasse como um instrumento potente para tensionar o nosso pensamento? $\mathrm{E}$ se assumíssemos esse campo de saber como aquele que resistisse aos modos hegemônicos de olhar para crise como o fim do nosso planeta? E se ela se colocasse na contramão do alarmismo barato que muitas vezes fizemos sobre as previsões futurísticas da ciência: o fim do mundo, os sinais do apocalispse?

Uma Educação Ambiental não da solução, mas do problema, da problematização, como nos ensinou Foucault $(2006,2014)$. Um desejo de fuga, de provocação ao instituído. Ao exposto. Às verdades educacionais. Aos modos clichês de vida verde.... A Educação Ambiental pode ser diferentes coisas e nisso está sua potência. Ela pode ser, como muitas vezes se apresenta na escola, a transversalidade que ensina como se comportar; ela pode ser tomada como solução para os problemas ambientais; ela pode ser uma infinidade de coisas. Ela pode ser também a resistência aos universalismos, uma ferramenta do pensamento; uma criação política de resistência ao instituído.

No entanto, para isso, é preciso compreender a importância de criarmos espaços de discussão e tensionamento a respeito dos fundamentos da EA, no sentido de entender como nos constituímos enquanto um campo de saber e o quanto as raízes modernas foram decisivas para existência de uma necessária Educação Ambiental. Exercendo a crítica sobre os fundamentos históricos, epistemológicos e filosóficos da EA potencializamos em nós o exercício da problematização para "tornar problemático tudo que é sólido" (FOUCAULT, 2014, p. 217). Examinando algumas das condições de possibilidade disso que se tornou uma grande consigna em torno do campo da Educação Ambiental - a crise - talvez pudéssemos, com o auxílio dos fundamentos históricos, epistemológicos e filosóficos, tensionar nossas heranças modernas. Não para negá-las, mas para potencializar em nós o desejo de resistir ao presente.

\section{Agradecimentos}

Esse artigo contou com financiamento da Coordenação de Aperfeiçoamento de Pessoal de Ensino Superior (CAPES), Estágio Sênior 2017-2018, processo n. 88881.119773/20 e do Conselho Nacional de Desenvolvimento Científico e Tecnológico (CNPq), Bolsista Produtividade 2 .

Agradeço às agências de fomento a possibilidade de contribuição científica em nosso país, especialmente em uma área que merece nosso debruçar em tempos atuais: o campo Educação Ambiental.

\footnotetext{
${ }^{3}$ Enunciações de capas da Revista Veja nos anos 2009 e 2006, respectivamente.
} 


\section{Referências}

109 vencedores do Nobel pedem fim de campanha do Greenpeace contra transgênicos. O Globo, Rio de Janeiro, 30 jun. 2016. Disponível em: https://oglobo.globo.com/sociedade/ sustentabilidade/109-vencedores-do-nobel-pedem-fim-de-campanha-do-greenpeace-contratransgenicos-19615289. Acesso em: 22 maio 2017.

BACON, F. Novum organum. 2. ed. São Paulo: Abril Cultural, 1979.

BERNARDO, A. La marcha por la ciencia en España comienza su andadura. Hipertextual, Madrid, 31 mar. 2017. Disponível em: https://hipertextual.com/2017/03/marcha-cienciaespana. Acesso em: 22 maio 2017.

BRASIL. Lei $n^{\circ} 9.285$ de 18 de julho de 2000. Regulamenta o art. 225, $\$ 1^{\circ}$, incisos I, II, III e VII da Constituição Federal, institui o Sistema Nacional de Unidades de Conservação da Natureza e dá outras providências. Diário Oficial da União, Brasília, 19 jul. 2000.

BRASIL. Ministério do Meio Ambiente. Unidades de conservação. [Brasília: MME, 2017]. Disponível em: http://www.mma.gov.br/areas-protegidas/unidades-de-conservacao. Acesso em: 26 maio 2017.

CARVALHO, I. C. M. Educação ambiental: a formação do sujeito ecológico. 4. ed. São Paulo: Cortez, 2008.

CARVALHO, I. C. M.; FARIAS, C. R.; PEREIRA, M. V. A “missão ecocivilizatória” e as novas moralidades ecológicas: a educação ambiental entre a norma e a antinormatividade. Ambiente \& Sociedade, Campinas, v. 14, n. 2, p. 35-49, 2011. DOI: http://dx.doi. org/10.1590/S1414-753X2011000200004.

CASTRO, E. V. A natureza em pessoa: sobre outras práticas de conhecimento. In: ENCONTRO VISÕES DO RIO BABEL: CONVERSAS SOBRE O FUTURO DA BACIA DO RIO NEGRO, 2007, Manaus. [Programação] Manaus: Instituto Socioambiental: Fundação Vitória Amazônica, 2007. Disponível em: https://docplayer.com. br/7499345-A-natureza-em-pessoa-sobre-outras-praticas-de-conhecimento.html. Acesso em: 2 ago. 2015.

DELEUZE, G. Foucault. São Paulo: Brasiliense, 1988.

DESCARTES, R. Discurso do método. São Paulo: Nova Cultural, 1996.

FOUCAULT, M. Arqueologia das ciências e história dos sistemas de pensamento. Rio de Janeiro: Forense universitária, 2005.

FOUCAULT, M. Estética: literatura e pintura, música e cinema. Rio de Janeiro: Forense Universitária, 2001.

FOUCAULT, M. Genealogia da ética, subjetividade e sexualidade. Rio de Janeiro: Forense Universitária, 2014.

FOUCAULT, M. História da sexualidade 2: o uso dos prazeres. 11. ed. Rio de Janeiro: Graal, 2006. 
FOUCAULT, M. Michel Foucault entrevistado por Hubert L. Dreyfus e Paul Rabinow. In: DREYFUS, H.; RABINOW, P. Michel Foucault: uma trajetória filosófica para além do estruturalismo e da hermenêutica. Rio de Janeiro: Forense Universitária, 1995. p. 251-268.

FOUCAULT, M. As palavras e as coisas: uma arqueologia das ciências humanas. 8. ed. São Paulo: Martins Fontes, 2002.

FOUCAULT, M. Vigiar e punir: nascimento da prisão. 25. ed. Petrópolis: Vozes, 2002a.

GODOY, A. O modelo da natureza e a natureza do modelo. São Paulo em Perspectiva, São Paulo, v. 14, n. 4, p. 129-138, 2000. DOI: https://doi.org/10.1590/S010288392000000400015.

GREENPEACE. Guía roja y verde de alimentos transgénicos. 5. ed. 2015. Disponível em: http://www.greenpeace.org/espana/Global/espana/2015/Report/transgenicos/ GuiaRojaVerdeTransgenicos_5edicion_Actualizacion062015.pdf. Acesso em: 24 maio 2017. GRÜN, M. Ética e educação ambiental: a conexão necessária. Campinas: Papirus, 1996. GRÜN, M. A outridade da natureza na educação ambiental. In: CARVALHO, I. C. M.; GRÜN, M.; TRAJBER, R. (org). Pensar o ambiente: bases filosóficas para a educação ambiental. Brasília: Ministério da Educação: Unesco, 2006. p. 177-188. Disponível em: http://portal.mec.gov.br/dmdocuments/publicacao4.pdf. Acesso em: 21 nov. 2018.

GUIMARÃES, L. B. Notas sobre o dispositivo da sustentabilidade e a formação de sujeitos verdes. In: SARAIVA, K.; MARCELLO, F. A. (org). Estudos culturais e educação: desafios atuais. Canoas: Ulbra, 2012. v.1, p. 219-232.

HENNING, P. C. Límites y posibilidades de la educación ambiental. Bajo Palabra: revista de filosofía, Madrid, v. 11, n. 17, p. 341-358, 2017.

MACHADO, R. Ciência e saber: a trajetória da arqueologia de Foucault. Rio de Janeiro: Graal, 1988.

MARCHA pela ciência: site oficial do Brasil. Disponível em: http://marchapelacienciasp. com. Acesso em: 22 maio 2017a.

MARCHA pela ciência leva milhares às ruas em atos pelo mundo. Folha de $\mathbf{S}$.

Paulo, São Paulo, 22 abr. 2017b. Disponível em: http://www1.folha.uol.com.br/ ciencia/2017/04/1877731-marcha-pela-ciencia-leva-milhares-as-ruas-em-atos-pelo-mundo. shtml. Acesso em: 26 maio 2017.

NIETZSCHE, F. A gaia ciência. São Paulo: Companhia das Letras, 2002.

NIETZSCHE, F. Sobre verdade e mentira no sentido extramoral. São Paulo: Hedra, 2008.

STENGERS, I. A invenção das ciências modernas. São Paulo: Editora 34, 2002. 
THOMAS, K. O homem e o mundo natural: mudanças de atitude em relação às plantas e aos animais, 1500-1800. São Paulo: Companhia das Letras, 1988.

VEIGA-NETO, A. Crise e as crises ambientais. In: GARCIA, R. L.; ESTEBAN, M. T.;

SERPA, A. (org.). Saberes cotidianos em diálogo. Rio de Janeiro: Faperj, 2015. p. 25-34.

WHY Greenpeace is wrong about GMOs and golden rice. Disponível em: http:// supportprecisionagriculture.org/why-greenpeace-is-wrong-about-gmos-and-golden-rice_rir. html. Acesso em: 22 maio 2017.

WORTMANN, M. L. C. Por que se valer do cinema, da mídia, da literatura, da televisão para discutir a natureza/ambiente? In: ZAKRZEVSKI, S. B.; BARCELOS, V. (org.). EA e compromisso social: pensamentos e ações. Erechim, RS: EDiFAPES, 2004. 
